\title{
Dynamic tension of aluminum alloy AMg-6 in a facility of Split Hopkinson Bar
}

\author{
Victor Pushkov ${ }^{1,2^{*}}$, Alexey Yurlov ${ }^{1}$, Valery Leonov ${ }^{1}$, Andrew Tsibikov $^{1}$, and Tatiana Naydanova ${ }^{1}$ \\ ${ }^{1}$ Russian Federal Nuclear Center - VNIIEF, 607190, Sarov, Nizhniy Novgorod region, Russia \\ ${ }^{2}$ Sarov Physico-Technical Institute NIYaU MEPhI, 607186, Sarov, Nizhniy Novgorod region, Russia
}

\begin{abstract}
The results are presented to create a facility for studying dynamic tension of structural materials by using the Split Hopkinson Bar Method (SHB method). The explosive method of loading and a cylindrical corner-rounding sample are used in a facility. A sample has threads at both end faces and it fastened in rods by the help of threads. The results of test experiments are presented in the facility for studying dynamic tension of the aluminum alloy AMg-6 at strain rates of 1160-1450 s $\mathrm{s}^{-1}$ The diagrams of dynamic tension $\sigma-\varepsilon$ were built. The data on peculiarities of deformation AMg- 6 were gained.
\end{abstract}

\section{Introduction}

To develop constructions, the experimental data are required concerning the behavior of materials under the different temperature-velocity loading conditions. One of the types of the experimental data relates to the results of dynamic tension of materials with strain rates of $10^{2}-10^{3}$ $\mathrm{s}^{-1}$. The data on dynamic tension are gained in many cases by using a Split Hopkinson Bar method (SHB method) [1-8]. For such experiments in the SHB method the cap-type samples were often used [2-4, 9]. In this case a loading bar was inserted into a cap, flanges of a cap rested on a support bar in the form of a tube [2-4]. In respect to a calculated description cylindrical samples of the fillet/corner-rounding type are more preferable [3,5], which are clamped in a thread on a loading bar and on a support bar (both bars are solid) [3, 7, 8]. In this case under loading a stress-strain state of a test portion of a cylindrical sample will be more uniform than the state of a cap-type sample [10].

The present work includes a facility of split Hopkinson bars to study dynamic tension of structural materials in cylindrical samples of the corner-rounding type. In similar devices, as a rule, pneumatic or hydropneumatic means are used for creating loads $[3,5,7,8$, 11]. In contrast to that an explosive method of loading is used here $[2,4,12]$. The results of test experiments are presented with regard to the studies of dynamic tension of the aluminum alloy AMg-6.

\section{Characteristics of a facility}

Figure 1 presents an installation diagram. Measuring bars made of titanium alloy VT16 represent the base of the facility. A diameter of bars is $20 \mathrm{~mm}$, a length of each bar is $1400 \mathrm{~mm}$, a cylindrical sample of the fillet type with a thread on end surfaces, a sample's test portion is $\varnothing 5 \times 8 \mathrm{~mm}$. A stress wave is generated in a facility by the help of explosion. The stress wave propagates on bars (Figure 1, items 4 and 8 ) and extends a sample (item 6). A cylindrical corner-rounding sample has threads on both end surfaces and this sample is clamped in bars with the use of the threads.

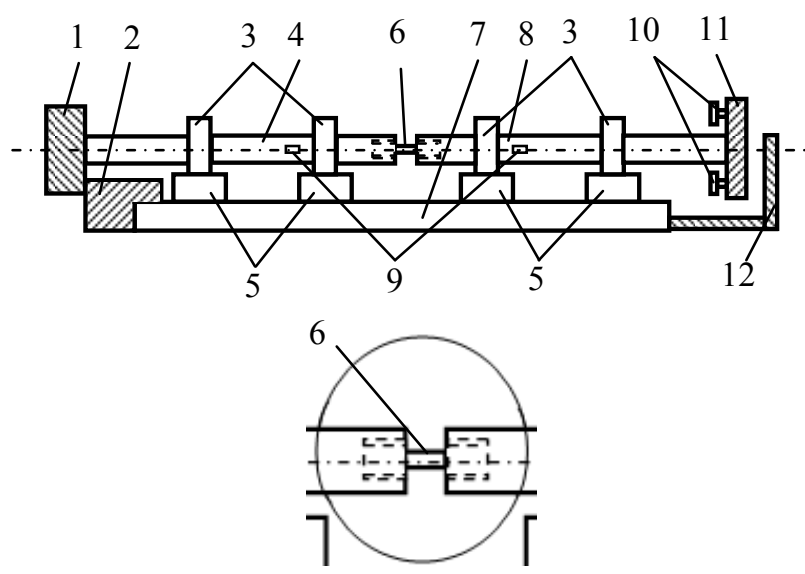

Fig. 1. Installation diagram of SHB for studying dynamic tensile test diagrams. 1,2 - limiting node, 3- directional elements, 4- support bar, 5- supports, 6-sample, 7- basechannel bar, 8- loading bar, 9- strain gauges, 10- node of explosive loading, 11 - impactor, 12- protective node.

A mechanical impulse creating a stress wave is formed by the help of a node of explosive loading (item 10 ), which is a steel disk with sticked HE, mounted on a pulse former (damper). A node of explosive loading (there can be up to 4 nodes) is fixed on an impactor (item 11) connected with a loading bar (item 8). In the course of HE explosion a damper is deformed and a mechanical impulse transmitted to an impactor creates a stress wave (tensile wave) in a loading bar (item 8) and in a sample. The disk (item 1) linked to a support bar, and the insert (item 2) are designed for eliminating movements of a

*Corresponding author: postmaster@ifv.vniief.ru 
support bar (item 4) at sample's loading. A protective node (item 12) serves to restrict movements of a loading bar in the case of sample's rupture under loading. Bars with a sample together with directional elements (item 3) and supports (item 5) are clamped on a base - channel bar (item 7). By using the records of elastic strains of bars recorded by strain gauges (item 9), as per the known formulas of the SHB method [1] the diagrams $\sigma-\varepsilon$ «stress-strain» are constructed.

Figure 2 presents basic geometrical sizes of samples; Figure 3 shows a photo of a facility with a sample.

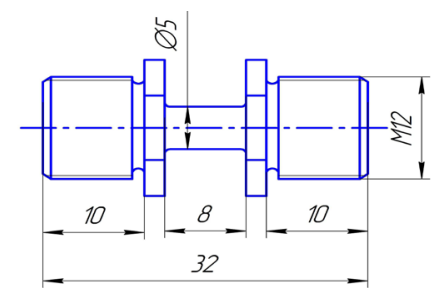

Fig. 2. Geometrical sizes of samples.

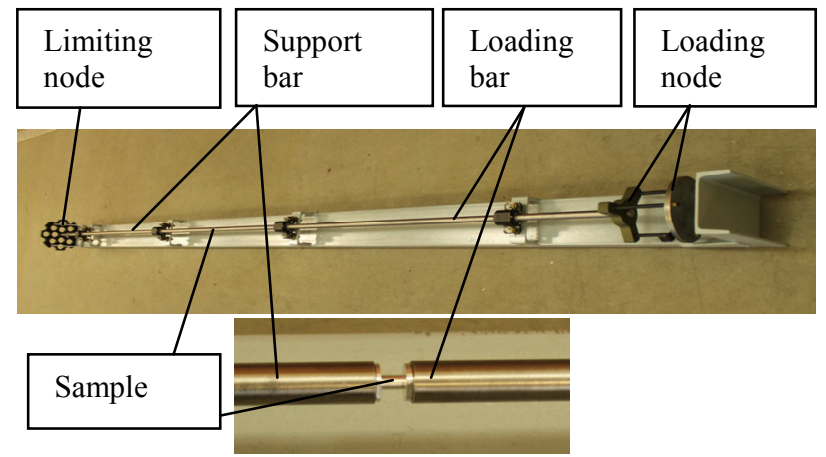

Fig. 3. Photos of a facility and a sample between rods.

The facility is designed for studying dynamic tensile test diagrams of materials in the range of strain rates from $10^{2}$ to $0,5 \cdot 10^{4} \mathrm{~s}^{-1}$ by using the SHB method.

\section{Results of test experiments}

Samples of aluminum alloy AMg-6 were made of a rod in as-delivered condition. 4 tests were implemented at dynamic tension; the strain rate $\dot{\varepsilon}$ in tests was $1160-1450$ $\mathrm{s}^{-1}$. Samples in tests were deformed and damaged; failure strain amounted to $25-35 \%$. A process of deformation and damage was recorded via a rapid video camera, a velocity of video filming amounted to $4 \cdot 10^{4}$ frames per second. In tests samples were destructed in the first stress wave propagating through a sample, when the wave did not yet interact with a wave reflected from a bar end face. Rapid video filming of a process confirmed this fact. Figure 4 presents frames of video filming of one of the tests, where a sample is presented prior to destruction with the formation of a neck, where a sample was already destructed and a photo of a sample after a test.

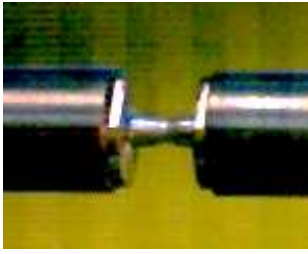

a) b)
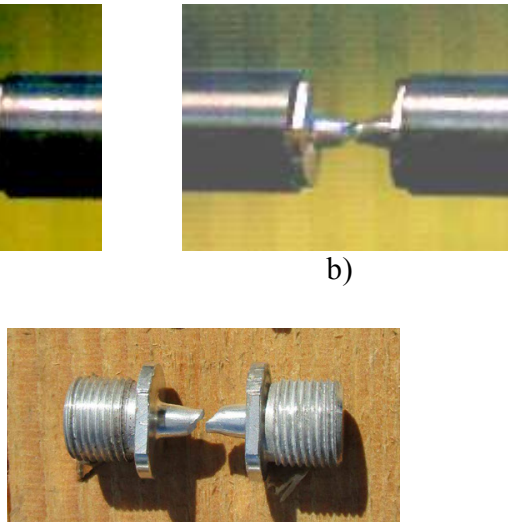

c)

Fig. 4. Video frames of a sample before fracture (a), of a fractured sample (b) and a photo of a sample after a test (c).

Each two halves of prototypes after testing were gathered together and residual failure strains were measured by a dial caliper. They accounted for $\sim 28 \%$ (for test №4) and 34-35\% (for tests №1-3). This confirms a good agreement between calculated and experimental data.

For illustration Figure 5 presents signals recorded by strain gauges on loading and support bars during the one of the tests.

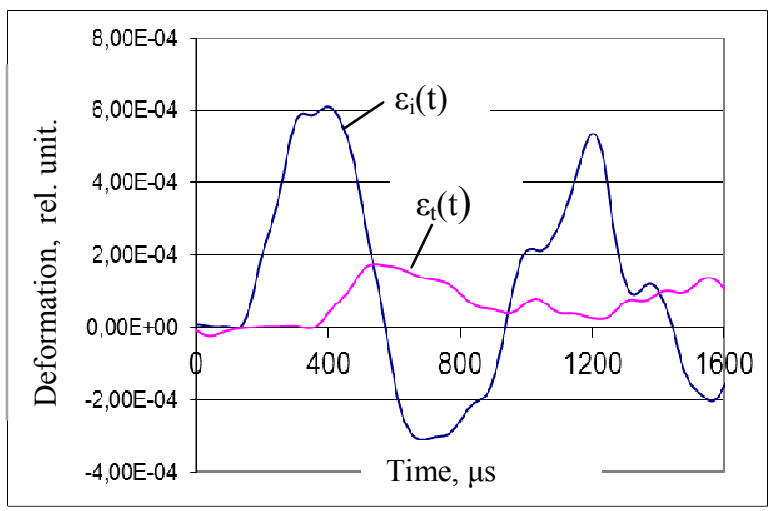

Fig. 5. Signals on loading bar $\left[\left(\varepsilon_{\mathrm{i}}(\mathrm{t})\right]\right.$ and support bar $\left[\varepsilon_{\mathrm{t}}(\mathrm{t})\right]$.

Figure 6 presents the $\sigma-\varepsilon$ test diagrams of AMg-6 dynamic tension constructed as per deformation pulses.

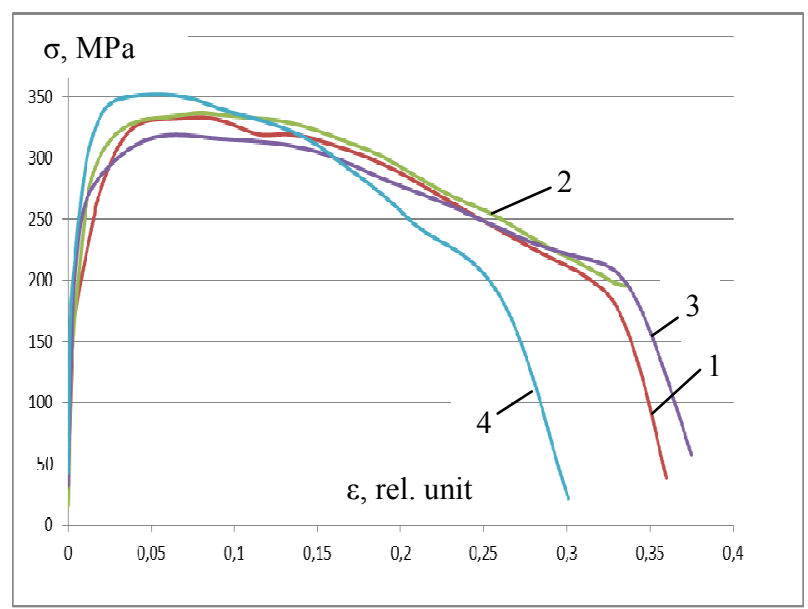

Fig. 6. $\sigma-\varepsilon$ test diagrams of AMg- 6 dynamic tension at $\dot{\varepsilon}=1160$ $1450 \mathrm{~s}^{-1}$. 
It is seen from the diagrams that after achieving a maximum stress (ultimate strength) samples are destructed not abruptly, but for a long time. A gently sloping form of falling areas of the $\sigma-\varepsilon$ diagrams corroborates this fact. And only by achieving deformation of $25 \%$ (test №4) and 33-35\% (tests №13) stress is being reduced drastically confirming that the final specimen destruction takes place.

The magnitudes of the yield strengths $\sigma_{0,2}$, the ultimate strengths $\sigma_{\mathrm{B}}$, the residual deformation $\delta$ in the course of fracture were determined from the gained diagrams. The results of the tests are given in Table 1. It was obtained that at the strain rates of $1160-1450 \mathrm{~s}^{-1}$ the yield strength $\sigma_{0,2}$ and the ultimate strength $\sigma_{\mathrm{B}}$ actually do not depend on a strain rate. The average value $\sigma_{0,2}$ in this range of strain rates amounts to $198.3 \mathrm{MPa}$, and the average value $\sigma_{\mathrm{B}}=335.3 \mathrm{MPa}$.

Table 1. Results of test.

\begin{tabular}{|c|c|c|c|c|}
\hline $\begin{array}{c}\text { № of } \\
\text { test }\end{array}$ & $\begin{array}{c}\boldsymbol{\varepsilon}, \\
\mathbf{s}^{-1}\end{array}$ & $\begin{array}{c}\mathbf{\sigma}_{\mathbf{0}, 2}, \\
\mathbf{M P a}\end{array}$ & $\begin{array}{c}\boldsymbol{\sigma}_{\mathbf{B}}, \\
\mathbf{M P a}\end{array}$ & $\begin{array}{c}\boldsymbol{\delta}, \\
\mathbf{\%}\end{array}$ \\
\hline 1 & 1300 & 184 & 333 & 33 \\
\hline 2 & 1160 & 187 & 337 & 35 \\
\hline 3 & 1450 & 210 & 319 & 34 \\
\hline 4 & 1200 & 212 & 352 & 25 \\
\hline
\end{tabular}

The value of $\sigma_{0,2}=205 \mathrm{MPa}$ was obtained in work [2] for AMg-6 under dynamic tension and a strain rate of $1700 \mathrm{~s}^{-1}$. It agrees well with the data obtained in the present work.

It is presented under static tension in a reference book [13] that for AMg-6 (sheet, profile, forged piece) the yield strength $\sigma_{0,2}$ amounts to $150-170 \mathrm{MPa}$, and the ultimate strength $\sigma_{\mathrm{B}}=300-340 \mathrm{MPa}$, as a whole they are 1.1-1.2 times lower than our obtained data. It points to AMg-6 sensitivity to an increase of a strain rate from static values $\left(10^{-3} \mathrm{~s}^{-1}\right)$ to dynamic values $\left(\sim 1200-1500 \mathrm{~s}^{-}\right.$ $\left.{ }^{1}\right)$. A similar tendency has been revealed in tests with AMg-6 for dynamic compression in work [14]. It confirms a good agreement of data.

\section{Conclusion}

The facility was created for studying dynamic tension of materials by using the SHB method with an explosive loading technique. Test experiments were implemented on a facility for studying dynamic tension of AMg-6 alloy. The samples of the corner-rounding type were tested with a test portion of $\varnothing 5 \times 8 \mathrm{~mm}$. Strain rates were implemented in tests in the range between 1160 and $1450 \mathrm{~s}^{-1}$.

The tensile test diagrams $\sigma-\varepsilon$ were constructed, the magnitudes were determined for the yield strength $\sigma_{0,2}$, for the ultimate strengths $\sigma_{\mathrm{B}}$ and residual deformation $\delta$ at failure. It was gained that at the strain rates of 1160$1450 \mathrm{~s}^{-1}$ the average value $\sigma_{0,2}=198.3 \mathrm{MPa}$, the average value $\sigma_{\mathrm{B}}=335.3 \mathrm{MPa}$, the magnitudes $\delta$ account for 25 $35 \%$. The obtained experimental data are in good agreement with literary data.

\section{References}

1. H. Kol'sky, Proceedings of the Physical Society, Section B, 62, 676-700 (1949)

2. A.P. Bol'shakov, S.A. Novikov, V.A. Sinitsyn, Problems of Strength (Rus), 10, 87-88 (1979)

3. A.M. Bragov, A.K. Lomunov, The use of the Kolsky method for dynamic tests of structural materials Applied problems of strength and plasticity: Collected articles of institutes of higher education, Nizhegorodskiy University (Rus), 51, 127-137 (1995)

4. V.A. Pushkov, A.P. Bol'shakov, G.A. Kvaskov, S.A. Novikov, V.A. Sinitsyn, Mechanical properties of uranium at quasi-static and shock-wave loading, Preprint, \#54-97, Sarov, RFNC-VNIIEF (1997)

5. E. Cadoni, D. Forni, Proceedings of the $11^{\text {th }}$ DYMAT International Conference, Switzerland, Lugano, EDP Science, Is-sur Tille, (01004-p.1)(01004-p.5) (2015)

6. A. Gilat and J. D. Seidt, Proceedings of the $11^{\text {th }}$ DYMAT International Conference, Switzerland, Lugano, EDP Science, Is-sur Tille, (01005-p.1)(01005-p.3) (2015)

7. K. Nakaia and T. Yokoyama, Proceedings of the $11^{\text {th }}$ DYMAT International Conference, Switzerland, Lugano, EDP Science, Is-sur Tille, (01039-p.1)(01039-p.6) (2015)

8. P. Kuhna, M. Ploeckl, and H. Koerber, Proceedings of the $11^{\text {th }}$ DYMAT International Conference, Switzerland, Lugano, EDP Science, Is-sur Tille, (01040-p.1)-(01040-p.6) (2015)

9. U.S. Lindholm, L.M. Yeakley, Exp.Mech., 1, 1-9 (1968).

10. A.M. Bragov, A.K. Lomunov, Int. J. Impact Engng. 16, \#2, 321-330 (1995)

11. V. Tarigopula, C. Albertini, M. Langseth, O.S. Hopperstad and A.H. Clausen, Proceedings of the $9^{\text {th }}$ DYMAT International Conference, Belgium, Brussels, EDP Science, Is-sur Tille, 381-387 (2009)

12. V.A. Pushkov, A.V. Yurlov, A.P. Bol'shakov, A.M. Podurets, A.V. Kal'manov and E.V. Koshatova, Proceedings of the $9^{\text {th }}$ DYMAT International Conference, Belgium, Brussels, EDP Science, Is-sur Tille, 395-400 (2009)

13. Physical quantitie, Reference book edited by I.S.Grigor'ev and E.Z.Meylikhov (Rus), Moscow, Energoatomizdat (1991)

14. V.A. Pushkov, S.A. Novikov, V.A. Sinitsyn, I.N. Govorunov, Proceedings of the $7^{\text {th }}$ DYMAT International Conference, Porto, Portugal, EDP Science, Les Ulis, 135-140 (2003) 
